\title{
Recovery of Particle Concentration Fields by Two-Phase Flow Visualization around Bodies
}

\author{
A.A. Zhelebovskiy',A, A.A. Mochalov²,A,B, A.Yu. Varaksin'3,A,B \\ A Bauman Moscow State Technical University, Moscow, Russia \\ в Joint Institute for High Temperatures, Russian Academy of Sciences, Moscow, Russia \\ ${ }^{1}$ ORCID: 0000-0003-2360-6665, zhelebovsk@gmail.com \\ 2 ORCID: 0000-0003-3078-1277, artem.mochalov@yandex.ru \\ 3 ORCID: oooo-0o02-8799-6378, varaksin a@mail.ru
}

\begin{abstract}
Measurement of the fields of particle concentration is one of the main task in research area of the two-phase flows around bodies in 'gas - solid particles' case. The paper considers the reconstruction of the concentration fields of solid particles by identifying their images. An experimental setup scheme for analysis of the structure of downward two-phase flow is presented. The main parameters of the experimental setup are as follows: geometry of the working area, air flow velocity, air flow rate, mass flow rate of particles. An optical monochrome setup for recording fast processes is briefly described. A method for processing experimental images based on the Canny edge detector is proposed. The processing algorithm for the experimental images was tested on glass microspheres used as a dispersed phase. The original image and a size distribution histogram for microstructures are presented. Examples of individual images of microspheres in a flow are considered for data validation. The experimental determination of the particle concentration fields in the downward flow and in the vicinity of the streamlined body are presented.
\end{abstract}

Keywords: visualization, high-speed camera, two-phase flow, density concentration, particle detection.

\section{Introduction}

The problem of interaction of the two-phase (dispersed) flows with streamlined bodies arises as part of analysis of the motion of various aircrafts in a dusty or rain atmosphere [1-3], and the flowing of two-phase coolants in channels of power facilities [4-6] as well. The presence of solid particles or drops may cause a significant (in some instances even multiple) increase of heat fluxes and erosion wearing of the streamlined surface. These phenomena are considered as a part of one problem due to a number of reasons: changing of characteristics of the incoming flow [7] and parameters of the boundary layer appearing on the streamlined body [8], appearing of vortex zones and turbulence traces, collisions of particles (or droplets) with the surface of the body [9, 10], changing of the surface roughness etc. The intensity of the processes that accompanies the two-phase flow around bodies depends on the inertia and the particle (droplets) concentration.

The main tasks of studying of two-phase flow around bodies are: 1) investigation of particles motion and determination of their characteristics - velocity fields, concentration etc. 2) determination of the influence of particles on the gas flow mode; 3) investigation of the interaction of particles with the streamlined surface [11], including erosion wearing, gas-dynamic sputtering [12-14], icing [15-18], illumination [19, 20] etc.

One of the tasks of the experimental investigation of two-phase flows is the determination of particles concentration fields in channels and in the vicinity of streamlined bodies as well. When performing these experiments, there is frequently a 
problem of ensuring the uniform spatial particles distribution at the entrance to the considered flow area. To estimate the uniformity of particles distribution over the channel cross-section area, we propose an algorithm determining their concentration after the series of frames shot.

This work is aimed to the visualization of time-averaged fields of particles concentration in the two-phase flow through a channel using high-speed video recording with the subsequent algorithmic processing of images obtained.

\section{Experimental unit to investigate the descending two- phase flows}

The experimental unit to investigate the two-phase flows (Fig. 1) is a vertical channel. The lemniscate inlet with feeder $\mathbf{1}$ is mounted at the entrance of the channel, through which is fed the disperse phase. The flow passes initial path $\mathbf{2}$ made of PVC and having the diameter of $100 \mathrm{~mm}$ and the length of $1000 \mathrm{~mm}$. Then via transfer path 3 the flow enters operational path $\mathbf{4}$, made of organic transparent glass (the square cross-sectional side 100 $\mathrm{mm}$ ). The length of operational path 4 is $500 \mathrm{~mm}$. Inside operational path 4 is mounted streamlined cylindrical body with a flat horizontal surface 5 having the diameter of $17 \mathrm{~mm}$. Outlet path 6 connects operational path 4 and cyclone type dust collector 7 , onto which fan $\boldsymbol{8}$ with the variable flow rate is mounted. The dispersed phase settles in the bins $\mathbf{9}$, mounted on cyclone 7 and outlet path $\mathbf{6}$. The experimental unit is mounted on steel frame 10.

Lemniscate inlet $\mathbf{1}$, transfer path $\mathbf{3}$, cylindrical body 5 and bins $\mathbf{9}$ are manufactured of polylactide (PLA) with the use of additive FDM-technology.

The flow rate of particles is varied within the range of $1-10 \mathrm{~g} / \mathrm{s}$ by the variation of the feeder cross-section area. The fan allows obtaining the air flow velocities up to $8 \mathrm{~m} / \mathrm{s}$.

In the process of video shooting, we use the lighting by LED floodlight 11 that is installed perpendicular to the channel axis (in the frame plane). To increase the uniformity of the floodlight illumination of the working area diffusion filters are used.

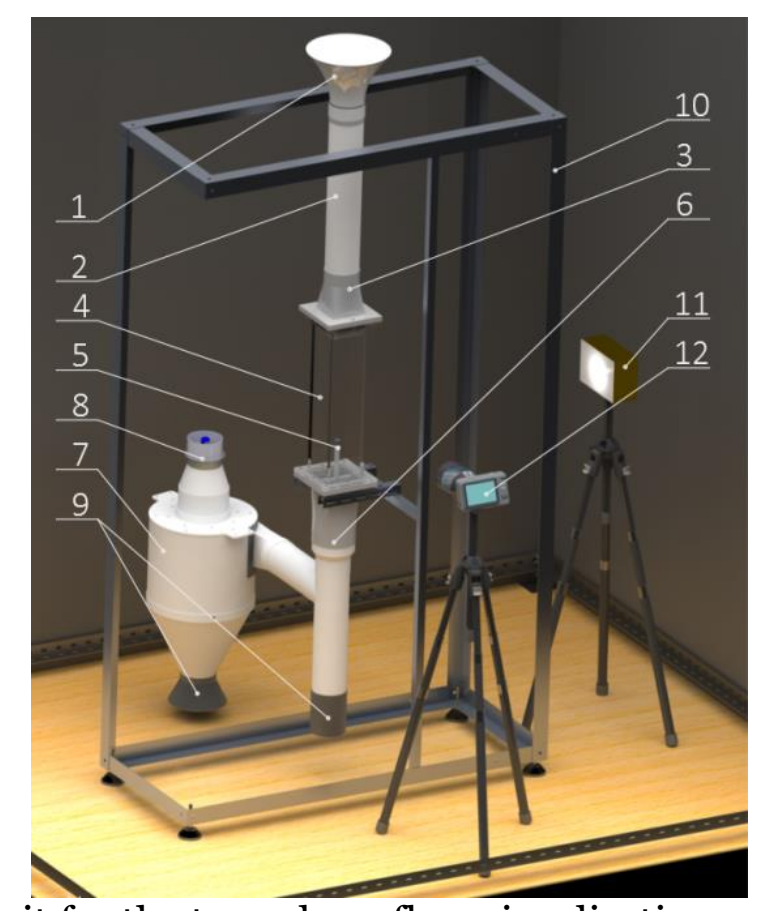

Fig. 1. Experimental unit for the two-phase flow visualization: 1 - lemniscate inlet with feeder; 2 - initial path; 3 - transfer path; 4-operational path; 5 - streamlined body; 6 outlet path; 7 - cyclone type dust collector; 8 - fan; 9 - bins; 10 - frame; 11 - LED

floodlight; 12 - high-speed camera 
As a dispersed phase in the experiments are used glass microspheres (Fig. 2) (the physical density of particles is $2550 \mathrm{~kg} / \mathrm{m}^{3}$ ) with the averaged diameter of $165 \mu \mathrm{m}$ (the mean square deviation of the diameter is $18 \mu \mathrm{m}$ ).

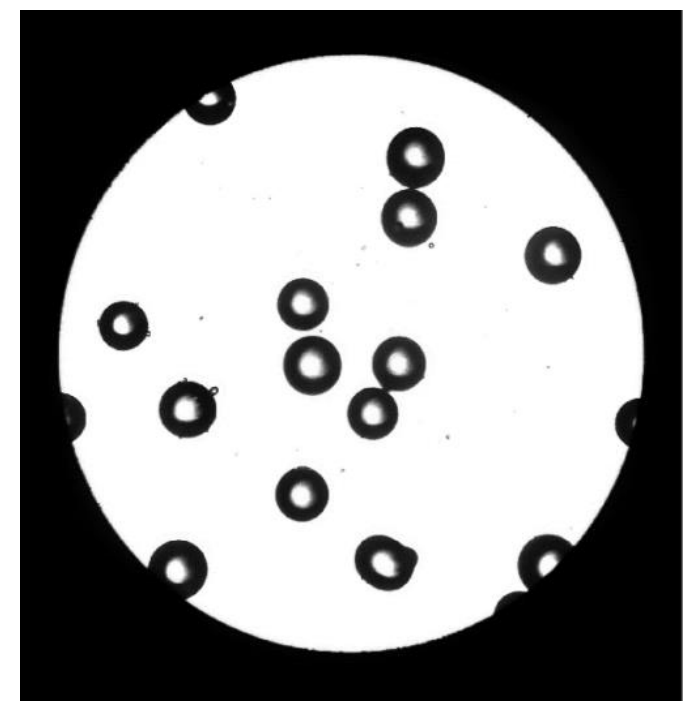

a

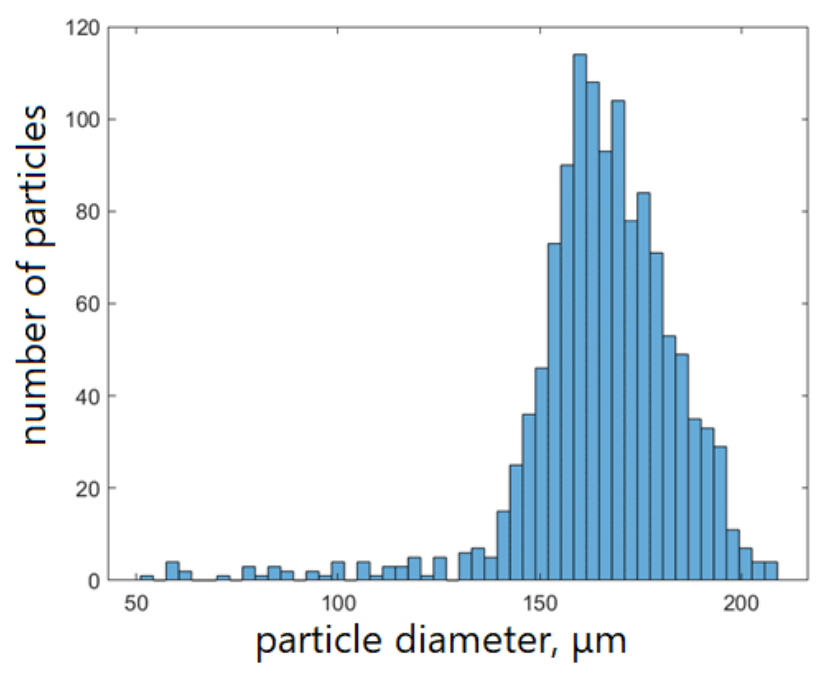

b

Fig. 2. Photo of particles at the 8ox magnification (a); histogram of the particles diameter distribution (b)

The video shooting of the flow volume under investigation is performed by the highspeed monochrome camera F 1500-32-M (Evercam, Russia) (Fig. 3). Its maximum resolution is $1920 x 1088$ pixels at a shooting speed of 1500 frames per second. The frame rate can be increased to 44000 frames per second, but in this case the resolution drops to $1920 x 16$ pixels. Zenitar Zenit 1,2/50s lens (Zenit, Russia) was used for shooting.

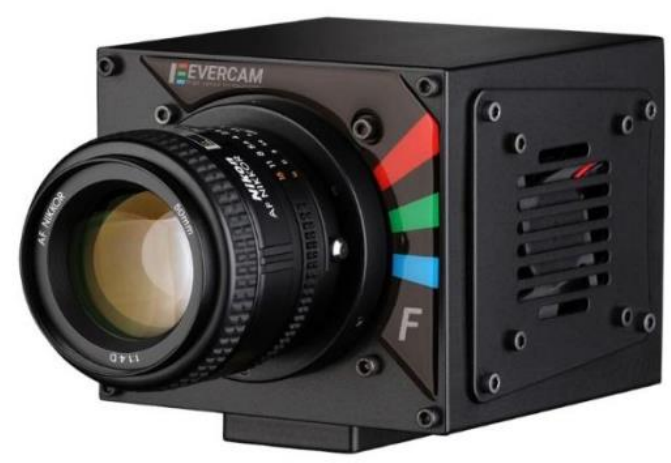

Fig. 3. High-speed monochrome camera Evercam F 1500-32-M

The unit has the following parameters: flow velocity (on the operational path axis) -3 $\mathrm{m} / \mathrm{s}$; particles mass flow rate $-2,4 \mathrm{~g} / \mathrm{s}$; air flow rate $-36,6 \mathrm{~g} / \mathrm{s}$. Video-shooting parameters: exposition time $-1 / 1500 \mathrm{~s}$; frame frequency $-2 \mathrm{~Hz}$; lens aperture $-\mathrm{f} / 2,0$; focal length of the lens $-50 \mathrm{~mm}$; resolution of frames $-1920 x 1088$ pixels. The experiment duration was 360 seconds.

\section{Technique of the particle identification}

For the problem discussed in this work, we have developed the software written in the MATLAB environment with use of the Image Processing Toolbox library. 
The initial data is a set of monochrome images (Fig. 4a) that are obtained experimentally. For the algorithm processing, the images were cropped to the region of interest and their inversion in the case of shooting with a shadow background method. Subsequently, the tone correction of the image was done, to obtain a sharper image of the particle boundary.

Then minimal value of each pixel for the total set of frames was computed. As a result, we obtained the image where there were no particles, but the elements of the unit were presented (walls of operational part, object under investigation, i.e. background image). The image of the minimum values was subtracted from the current set, pixel-by-pixel (Fig. 4b). Particle boundaries became sharper and background noise increased significantly.

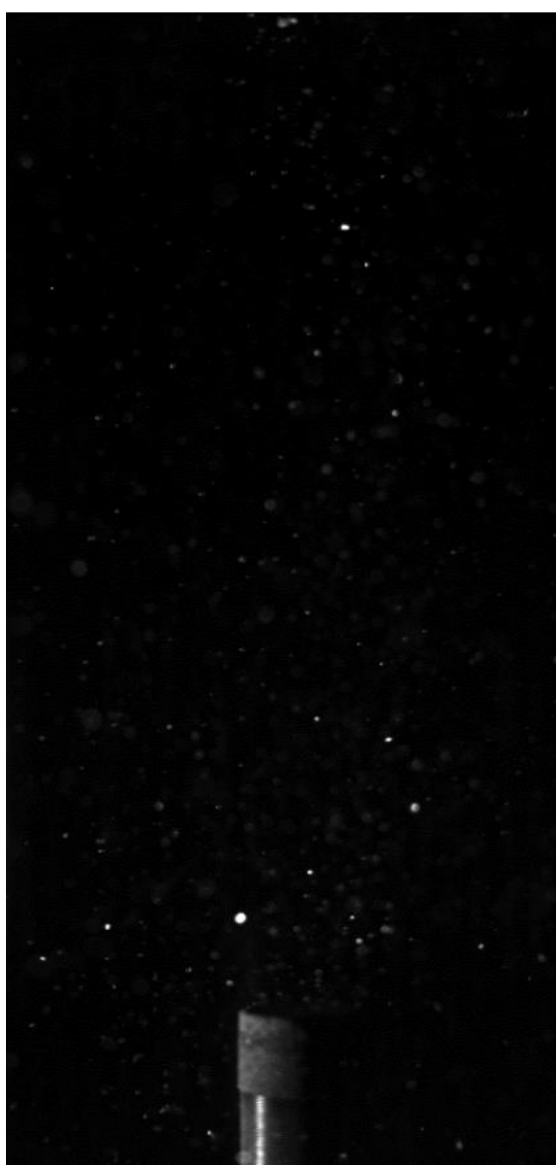

a

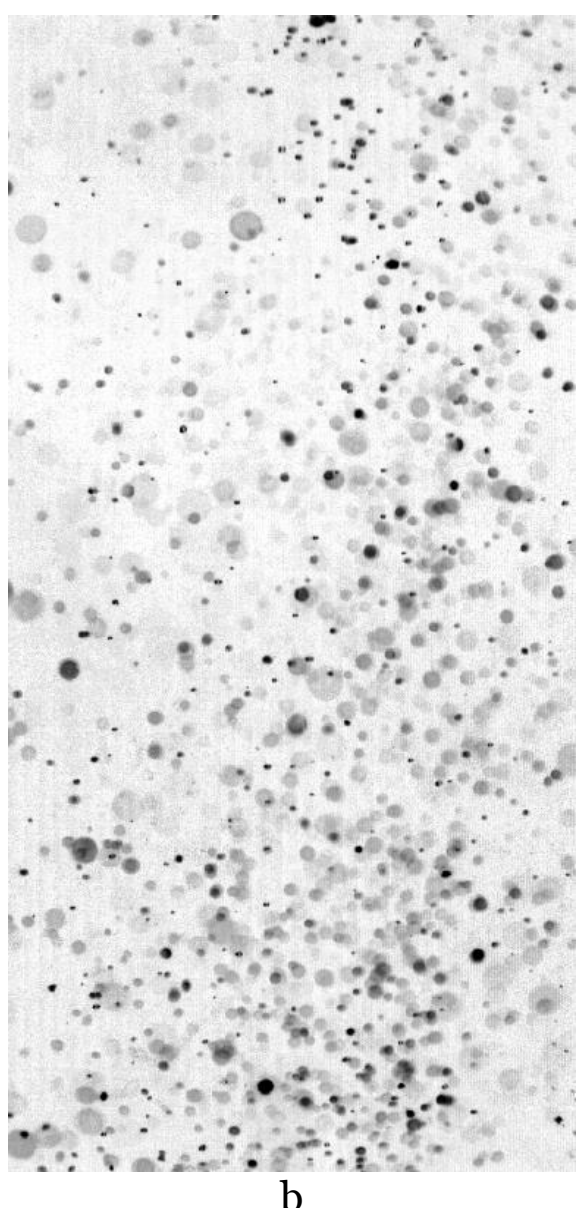

$\mathrm{b}$

Fig. 4. Initial image (a); cropped inverted image with the subtracted background (b)

The particle boundaries are detected with the technique developed by J. F. Canny [21]. The latter allows obtaining the binary image of boundaries. Closed areas imaging the particles are filled in. False images of open boundaries are discarded (Fig. 5a) using the morphological opening operation. From the binary particle image, some parameters are estimated, i.e., position of the centers of mass of the particles (Fig. 5b), area, initial particle image, direction of the main central axes. Each image representation is extended with a set of estimated parameter values assigned for the found particles. 


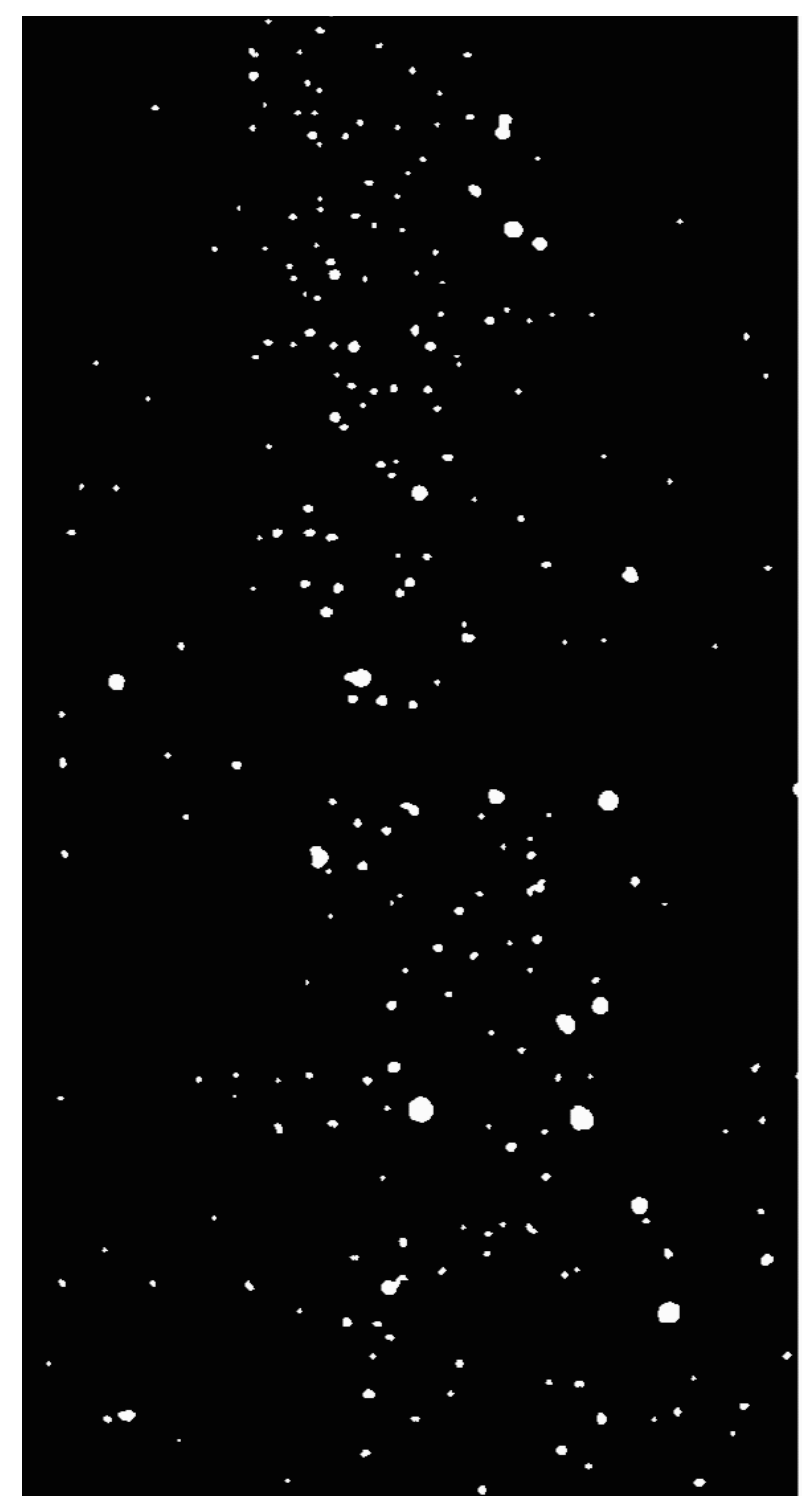

a

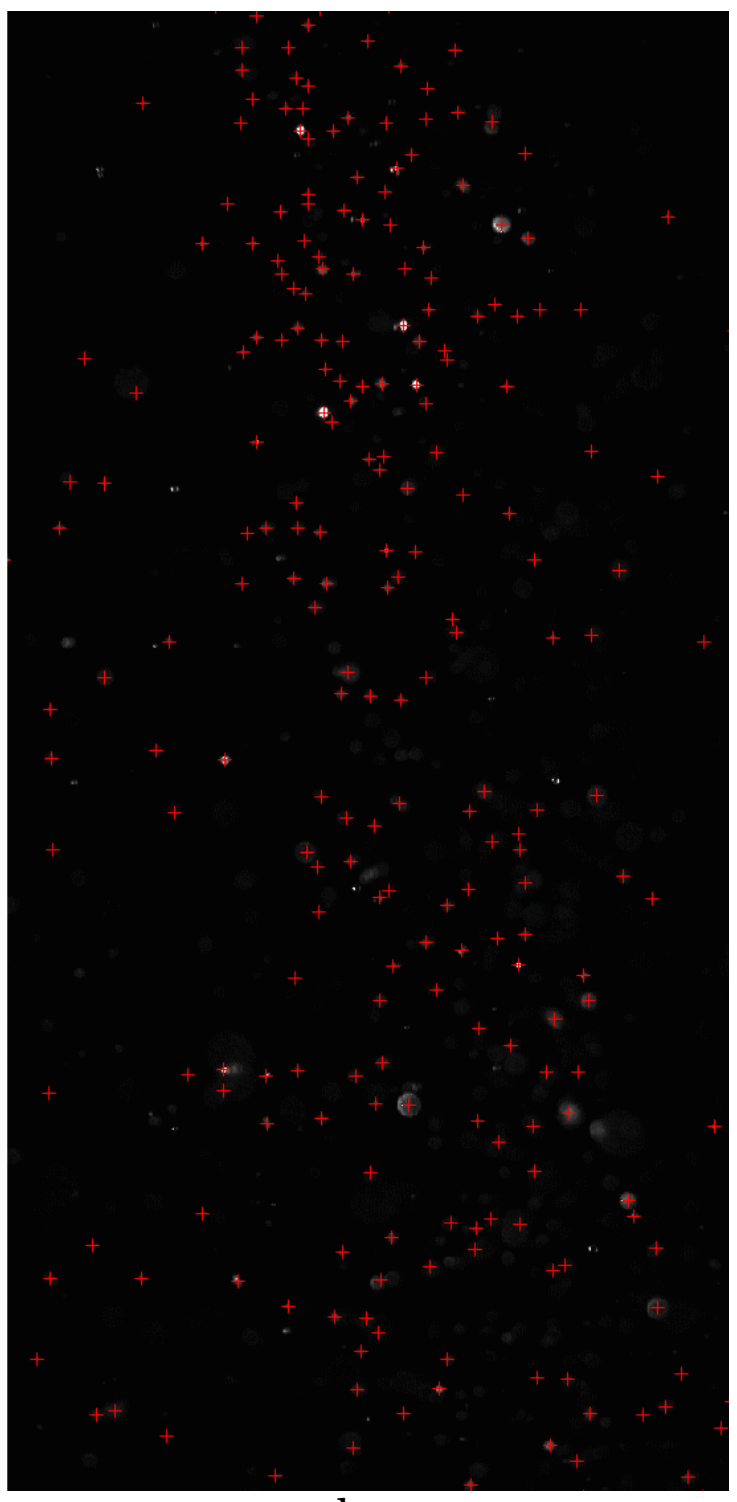

b

Fig. 5. Particle boundary binary image (a); particle center of mass locations (b)

We filter the obtained set of the images by the average value of the particle image intensity (Fig. 6), thus considering only those that are essential for the further analysis. During the shooting, one should keep in mind the depth of the sharply depicted space: when the aperture is open, although the aperture of the optical system is the largest, the area of sharpness of the image is reduced. This results in, that the images of particles near the back and front wall of the operational pass become unsharp. (Fig. 6b). In this case, the identified particles are less likely to pass the average image intensity test. 


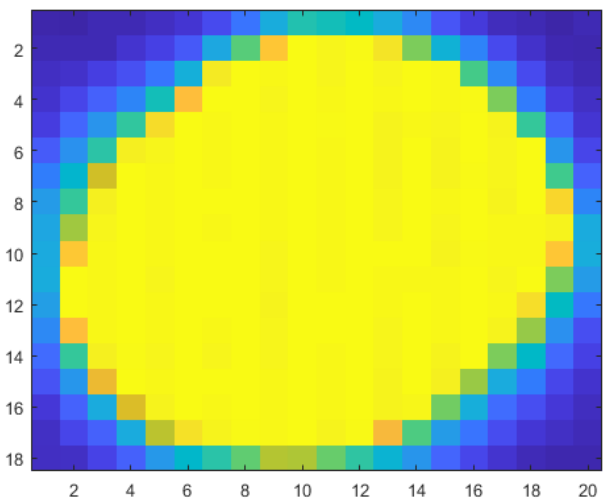

a

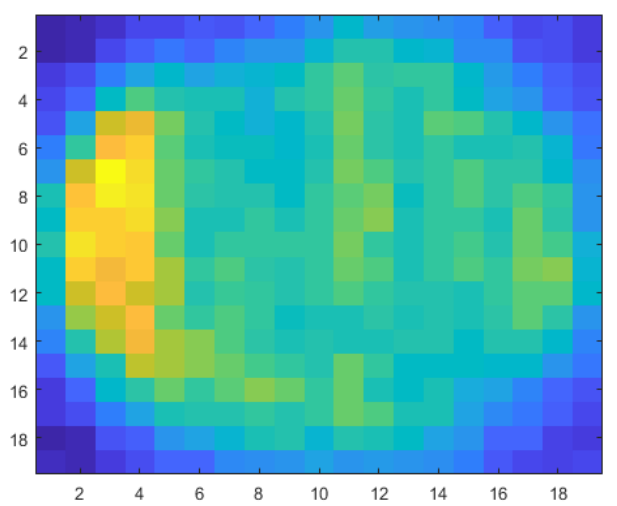

$\mathrm{b}$

Fig. 6. Examples of single particle images: sharp image (a); unsharp image (b)

\section{Making up of averaged fields of particles concentration}

One of the key characteristics of two-phase flows is the spatial distribution of particles. The data obtained with the use of particle identification algorithm may be represented with a so-called heat map. The area of the operational pass image to be processed is split into cells, each of $20 x 20$ pixels. Subsequently, it is calculated the number of particles in each cell over the total set of photos (Fig. 7a). The ratio of the number of particles in a cell under calculation over all the frames to the total number of frames determines the average quantity of particles $n_{p}$ in the given cell.

The feeding of particles into the flow occurs via the hole ( $4 \mathrm{~mm}$ of diameter) in the feeder, what is $1 / 25$ of the transversal size of the operational channel. From Fig. $7 \mathrm{~b}$ one can see, that the disperse phase, after passing the initial path, comes into the operational path with the non-uniform distribution over the cross-section area: there is a concentration growing from the walls to the channel axis. The opening angle of the jet relative to the channel axis is approximately $5-7^{\circ}$. When the flow approaches the end of the streamlined body, a sharp increase in concentration takes place (in 2 and more times), due to the contribution of reflected particles moving in the opposite direction towards the main flow. In the conditions of the low-dust flow, the oncoming particles reach a height of about three diameters of the end face what enables the effect of surface shielding. 


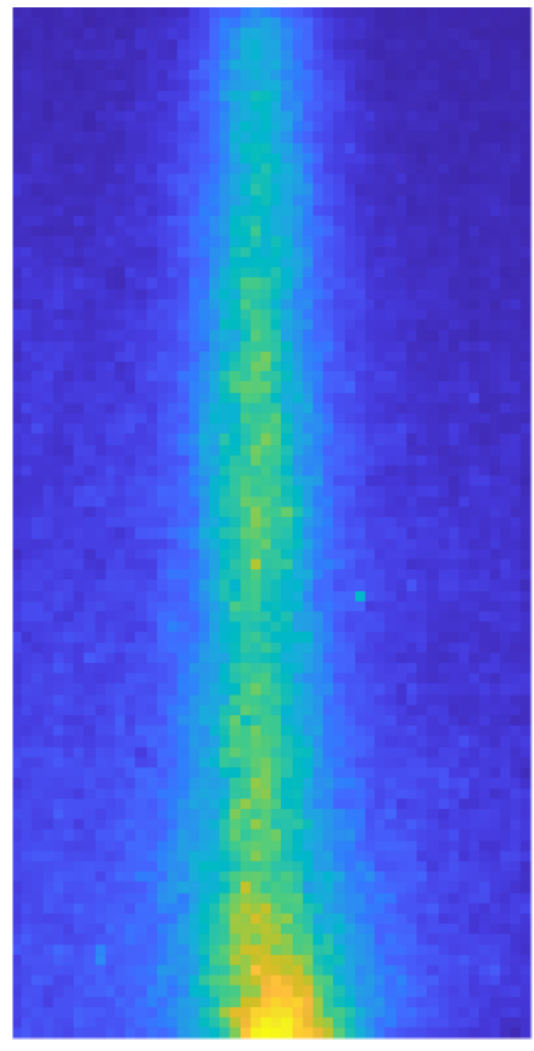

a

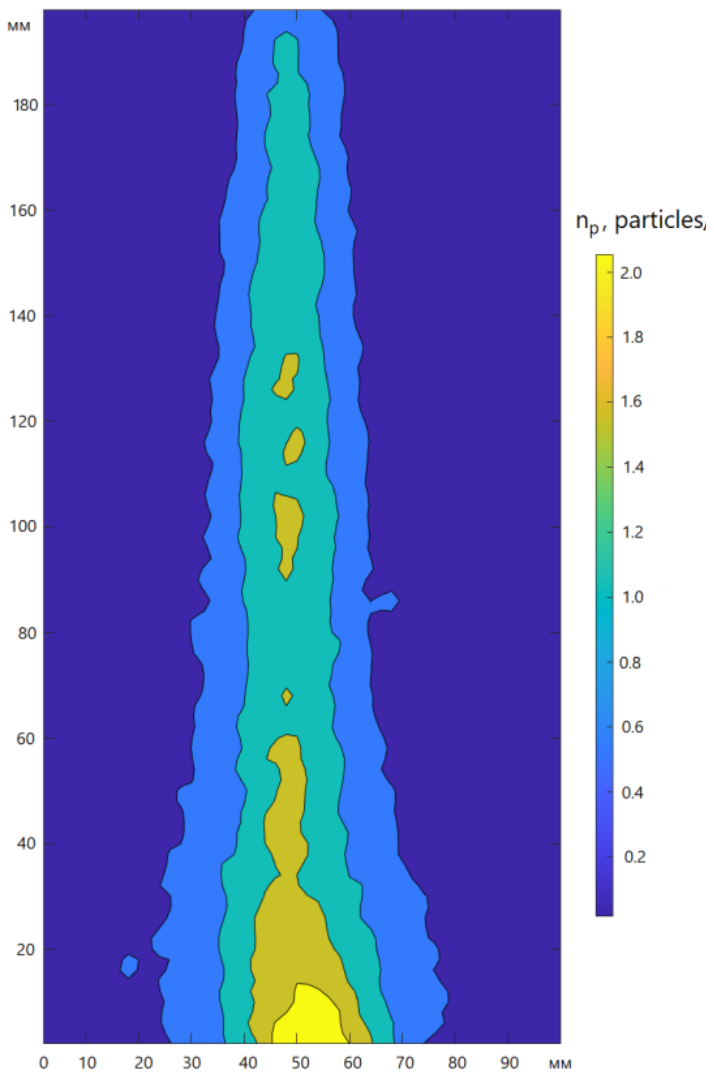

b

Fig. 7. Distribution of particles over the operational pass: heat map of square cells (a); contour plot (b)

\section{Conclusion}

We have discussed the problem of the detection of the fields of particles concentration in a multiphase flow with the use of the algorithm developed by J. F. Canny. Application of the technique proposed to the flow with the glass microspheres showed a fairly reliable result, which is consistent with the experimental images taken separately from the sample. There had been obtained particles distributions over the operational path cross-section area and their frame-by-frame images. The further visual interpretation proposed demonstrates, e.g., a rapid growing of the particle concentration in the vicinity of the streamlined body. The proposed technique can be of interest for the investigation of surface shielding in dusted flows.

\section{References}

1. Teoriya i proektirovanie gazoturbinnyh i kombinirovannyh ustanovok [Theory and Design of Gas Turbine and Combined Plants]. Varaksin A.Yu. Ed. Moscow: Mosk. Gos. Tekh. Univ. im. N.E. Baumana, 2017.

2. Mikhatulin D.S., Polezhaev Yu.V., Reviznikov D.L. Teploobmen i razrushenie tel v sverhzvukovom geterogennom potoke [Heat Transfer and Destruction of Bodies in a Supersonic Heterogeneous Flow]. Moscow: Yanus-K, 2007.

3. Mikhatulin D.S., Polezhaev Yu.V., Reviznikov, D.L., Teplomassoobmen, termokhimicheskoe i termoerozionnoe razrushenie teplovoi zashchity [Heat and Mass Transfer, Thermochemical and Thermal Erosion Destruction of Thermal Protection]. Moscow: Yanus-K, 2011.

4. Sukomel A.S., Tsvetkov F.F., Kerimov R.V. Teploobmen i gidravlicheskoe soprotivlenie pri dvizhenii gazovzvesi v trubakh [Heat Transfer and Hydraulic Resistance during the Movement of Gas Suspension in Pipes]. Moscow: Energiya, 1977. 
5. Deich M.E., Filippov G.A. Gazodinamika dvukhfaznykh sred [Gas Dynamics of TwoPhase Media]. Moscow: Energoizdat, 1981.

6. Perel'man R.G., Pryakhin V.V. Eroziya elementov parovykh turbin [Erosion of Steam Turbine Components]. Moscow: Energoatomizdat, 1986

7. Varaksin A.Yu. Effect of particles on carrier gas flow turbulence. High Temperature, Vol. 53, № 3, 2015, P. 423-444.

8. Varaksin A.Yu. Two-phase boundary layer of gas with solid particles. High Temperature, Vol.58, № 5, 2020, P. 716-732.

9. Varaksin A.Yu. Collision of particles and droplets in turbulent two-phase flows. High Temperature, Vol.57, № 4, 2019, P. 555-572.

10. Varaksin A.Yu. Two-phase flows with solid particles, droplets, and bubbles: problems and research results (review). High Temperature, Vol.58, № 4, 2020, P. 595614.

11. Varaksin A.Yu. Collisions in Particle-Laden Gas Flows. New York: Begell House, 2013.

12. Kiselev S.P., Kiselev V.P., Klinkov S.V., Kosarev V.F., Zaikovskii V.N. Study of the gas-particle radial supersonic jet in the cold spraying. Surface \& Coatings Technology, Vol. 313, 2017, P. 24-30.

13. Klinkov S.V., Kosarev V.F., Shikalov V.S. Influence of nozzle velocity and powder feed rate on the coating mass and deposition efficiency in cold spraying. Surface \& Coatings Technology, Vol. 367, 2019, P. 231-243.

14. Fomin V.M., Golyshev A.A., Kosarev V.F., Malikov A.G., Orishich A.M., Filippov A.A. Deposition of cermet coatings on the basis of Ti, Ni, WC, and B4C by cold gas dynamic spraying with subsequent laser irradiation. Physical Mesomechanics, Vol. 23, 2020, P. 291300.

15. Fortin G., Ilinca A., Laforte J.-L., Brandi V. A new roughness computation method and geometric accretion model for airfoil acing. J. of Aircraft, Vol. 41, № 1, 2004, P. 119127.

16. Alekseenko S.V., Prikhod 'ko A.A. Mathematical modeling of ice body formation on the wing airfoil surface. Fluid Dynamics, Vol. 49, № 6, 2014, P. 715-732.

17. Takahashi T., Fukudome K., Mamori H., Fukushima N., Yamamoto M. Effect of characteristic phenomena and temperature on super-cooled large droplet icing on NACA0012 airfoil and axial fan blade. Aerospace, Vol. 7, № 7, 2020, Paper No. 92.

18. Min S., Yee K. New roughness-induced transition model for simulating ice accretion on airfoils. AIAA Journal, Vol. 59, № 1, 2021, P. 250-262.

19. Molleson G.V., Stasenko A.L. Gas thermodynamics and optics of a monodisperse supersonic jet interacting with an aerodynamic body. High Temperature, Vol. 50, № 6, 2012, P. 755-764.

20. Molleson G.V., Stasenko A.L. Electro-optical phenomena in a gas-dispersed jet flow around a solid body. High Temperature, Vol. 53, № 6, 2015, P. 855-864.

21. Canny J. F. A computational approach to edge detection. IEEE Trans. Pattern Analysis and Machine Intelligence, Vol. 8, 1986, P.678-698. 